\section{REGIONAL REPORTS}

Sports injuries in the European Union member states: a "team sport" project

Exercise should be an integral part of every day activities if we are to promote a healthy lifestyle and successfully combat the contemporary nosological spectrum. Participation in sports activities has always been thought of as enhancing physical and mental health; and as such, it should be strongly encouraged for both youth and adults. Sports injuries, on the other hand, constitute an unwanted side effect of practising not only strenuous but also regular physical exercise. There has been no systematic effort in the European Union (EU) countries, however, to comprehensively ascertain the burden of this type of injury despite the fact that this information is a prerequisite for the development of $\mathrm{EU}$ policies and for designing injury prevention programs. CEREPRI has conducted a project entitled "Sports injuries in the view of the 2004 Olympics: harvesting information from existing databases" supported by the Division General for Public Health aiming to address the magnitude and the dimensions of the sports injuries problem in the EU member states.

The specific aims of this project were to:

(1) Explore the ability of the former EHLASS database to capture sports injuries, analyse currently available information that is isolated or under-utilised at the national level, and identify deficiencies, inadequacies, or limitations.

(2) Ascertain the burden of sports injuries in EU member states by type of injury, using complementary sources of information and ad hoc approaches,

(3) Develop a set a public health indicators for sports injuries.

(4) Promote the exchange of information about the use of sports injuries data.

\section{Building a EU alliance for sports} injuries documentation and prevention

Official partners in the project were colleagues representing Institutions from five EU member states (Austria, France, Germany, Italy, and Greece) and Israel, with additional input from the Netherlands, Denmark, USA, UK, and the European Commission.

The first goal of the project team was to reach a unanimous definition for sports injuries. No definition is perfect, but the criteria for the one used in this project were simplicity, easiness in use, and reliability. Subsequently, each participating institution was asked to exploit existing data sources, elicit information and draft a national report, on the basis of data describing the magnitude and the dimensions of the sports injury problem. It was evident that the burden of sports injuries and their sequelae, especially among elite athletes who frequently make use of private health care services, was not well captured by EHLASS; thus, this database had to be complemented - to a various extent, depending on the country information from other sources. To this end, a large variety of sources were searched, including national health surveys, the national statistical service departments, insurance companies files, archives of sports and youth organizations, medical records kept by private sports physicians and physiotherapists, antidoping centers' releases and lastly, athletic newspapers' clips.

Time exposure data by type of sporting activity were rarely available, but information on the range of sports most frequently practised in each country was made available by most participating countries and formed the basis for the compilation of an inventory describing the most popular sports in the EU.

People living in EU countries are characterized by cultural diversity, different degrees of practising the diverse sporting activities, whereas the respective member states provide infrastructure of variable quality and have different levels of sports injury prevention philosophy. This 18 month duration of the first phase of the project comprised a fertile soil for the development of an interactive process among the participating organizations. Moreover, multiple opportunities were given to the project participants to link their common interests and activities, to discuss concerns and emerging issues during prescheduled meetings with national coordinators, and to use informal communication channels in order to share common concerns about sports injuries prevention and control. Each member state was urged to contact as many national bodies as possible, out of those involved in sports activities and concerned with sporting safety. Countries, lacking formal registration systems - especially with regards to professional sports injuriesathletes, sports physicians, physiotherapists and coaches, administrators in athletic and youth organizations, reporters on athletics, sports and health academics contributed valuable quantitative and qualitative information and personal views about the development of pertinent sports injury prevention strategies.

A global report was thus compiled on the basis of published and unpublished information provided by national experts, that included results of data analysis on sports injuries in individual member states and figures describing injury probabilities due to practising specific sports activities. Apart from EHLASS data, however, most other sources did not yield comparable data. Thus, despite its inadequacies EHLASS remains at the EU level the sole surveillance system that can be used for proportional comparisons among member states. Data from international bodies were also gathered showing increased doping detection proportions during major athletic competitions.

In order to satisfy the expressed need for development of priority policies for sports injury prevention and control across the EU, a set of indicators was developed and approved by the participating EU member states and Israel. These indices could be used to determine with reasonable accuracy, the overall dimensions of the problem and could be made available to political leaders and health authorities, which are interested in addressing relevant issues. Injuries during sporting activities seem to represent a sizeable proportion of all injuries, especially among the younger population groups. Overuse injuries as well as the impact of performance enhancing substances on the injury rate needs to be further studied in the $\mathrm{EU}$ member states and pertinent methodologies to address this sensitive issue need to be developed and implemented. Lastly, long term sequelae of sports' injuries cannot be assessed through the established data collection systems and only few investigations have been undertaken with this respect.

In conclusion, the context of this EU project provided a unique opportunity for scientists of the participating member states to join forces, exchange experiences aiming to produce policy recommendations for sports injury prevention and control in this part of the world. More specifically, during the first phase of this project an attempt was made to bring to light the fragmented but diverse EU experience on assessing the magnitude of sports injuries. Identification of risk factors and evaluation of currently used prevention measures have been planned for the second phase of the project, which has already been started. Recommendations to international injury classification committees and standardization bodies or consumer safety organizations are to be made, whereas effective interventions in the European scene and around the world are to be monitored and examples of good practice are hoped to be presented.

An Executive Summary of the report is available on request. We are interested to receive ideas and experiences from other parts of the world. Communications for this Sports Safety Alliance should be directed to Eleni Petridou, Project Manager, Director, CEREPRI at epetrid@cc.uoa.gr.

$M$ BELEHRI

E PETRIDOU

Center for Research and Prevention of Injuries among the Young (CEREPRI),

Department of Hygiene and Epidemiology, Athens University Medical School,

Athens, Greece

\section{SAFE KIDS Worldwide launched}

More than 40 public health, medical, and business professionals from 18 countries convened in Washington, DC in January 2001 to attend the first ever SAFE KIDS Worldwide Leadership Conference entitled, "Building the Global Team". The countries represented were Australia, Austria, Brazil, Canada, Germany, Greece, Israel, Japan, Korea, Mexico, New Zealand, Philippines, South Africa, Spain, United Arab Emirates, United Kingdom, United States, and Vietnam.

The SAFE KIDS Worldwide mission is to prevent unintentional injury to children across the globe. It is a network of childhood injury control programs that successfully link organizations, communities, and the private sector in effective philanthropy and cause marketing to better protect children. Members of the SAFE KIDS Worldwide network are committed to the SAFE KIDS model that includes:

- Sound scientific research to address childhood injuries.

- Grassroots coalition building for implementation of prevention activities.

- Activation of public policy efforts.

- Sophisticated communications strategies to create national awareness.

- Proven, cost effective interventions to prevent childhood injury that are tailored to customs and conditions of each culture. 
SAFE KIDS Worldwide will join public and private organizations, health care professionals, government officials, corporate executives, and others committed to childhood injury prevention. For additional information, please contact: Camilla Taft, $\mathrm{MPH}$, SAFE KIDS Worldwide Manager, at ctaft@safekids.org.

A MICKALIDE National SAFE KIDS Campaign, 1301 Pennsylvania Avenue, NW, Suite 1000, Washington, DC 20004, USA Tel: +1 202 662-0603, fax: +1 202 393-2072 amickalide@safekids.org

\section{European Child Safety Alliance}

With the support of the European Commission and the Consumer Safety Institute of the Netherlands, the European Consumer Safety Association has been able to fulfill one of its ambitions: to create a long lasting platform to coordinate European promotions and advocacy work that will increase the profile of child injury prevention and place it on the political agenda, through the networks of dedicated national societies.

More specifically, in the field of child safety and through the efforts of a newly established European Child Safety Alliance, we will advocate to achieve safer daily living for children throughout Europe. This would include consistency of standards, policies, and legislation used throughout Europe that impacts children's safety, as well as assisting parents and caregivers to be well informed consumers in order to make the right choices for children. Moreover, we will try to influence the environment so that families would have a selection of child safety products that are accessible for families. These products would be affordable for families to purchase, and easy to use so their safety value is not lost in misuse. We hope to improve the lives of children in Europe so all those whom have an impact on them, would make decisions and choices that use what has been proven to work, as well as keeping the interest of children a first priority.

The alliance will emphasize strategies that will assist in the reduction of deaths and disability to children due accidents to children $0-18$ years of age in the EU member states. Over the next three years (2001 to 2003) accidental injuries and deaths among children $0-4$ years will be the focus of activities. We intend to concentrate on promoting the wider application of safety technologies that are simple to install and that have already been proven to be effective.

The scope of work will include the areas of:

- Accident and risk factor analysis.

- Product safety and technology.

- Standardization and enforcement.

- Education and campaigns.

The work will be done in partnership with multidisciplinary stakeholders involved in child injury prevention to promote a coordinated and consistent approach across Europe. The European Child Safety Alliance will operate using evidence based research to determine its priority issues and strategies. These strategies will be delivered using stakeholders and partners in the member states in order to reach a diverse audience. Strategies will incorporate multifaceted approaches to enhance the level of success in reducing injuries including engineering, enforcement, and education.
It is hoped that the alliance will serve as the European catalyst through which national and international networks and activities are facilitated to advance advocacy for European legislative and funding changes, broad social marketing campaigns, and an injury communications network to share best practices/ successful programming, and information needs.

The alliance is guided by a steering group, composed of representatives from national child injury prevention agencies in the $15 \mathrm{EU}$ member states and affiliated child safety organizations. A business plan outlining the specific activities of the alliance is being drafted and has been available for review from March 2001. To review this plan and obtain more information about the European Child Safety Alliance, please check the European Consumer Safety Association web site at www.ecosa.org.

J VINCENTEN

Director, European Child Safety Alliance j.vincenten@consafe.nl

\section{LETTER TO THE EDITOR}

\section{Scooter injuries to children}

EDIToR,- Recent injury data collected by the Victorian Injury Surveillance and Applied Research System (VISS), suggests the current resurgence in scooter use by children is associated with increases in the numbers of children injured, some extremely seriously.

Scooter injuries to children have increased from an average of 9.5 annually (1996 to 1999) to 153 cases predicted for 2000 if there is no further increase in scooter exposure. This figure is based upon 128 cases of injury for January to September 2000. However, considering the observed monthly rate of growth in scooter exposure, we project as many as 320 scooter related injuries in Victoria alone for $2000 \quad\left(\mathbf{R}^{2}=0.97\right.$, $\left.y=0.20 x^{3}-0.27 x^{2}-2.48 x+47.67\right)$. Nationally, between 750 and 1500 Australian children may suffer injury as a result of riding a scooter by the end of 2000 .

Data for the first nine months of 2000 reveals the majority of scooter related injuries are to children aged $10-14$ years $(55.5 \%)$. Compared with 1999, the first nine months of 2000 are associated with a sixfold increase in injuries to children aged less than 4 years $(p<0.001)$ and a close to fivefold increase (4.7) in injuries to children aged 10-14 years $(p<0.001)$. Interestingly, there has been a 15 -fold increase in injuries sustained by children aged $5-9$ years $(\mathrm{p}<0.001)$.

More males $(64.1 \%)$ than females were injured while using scooters and $10.2 \%$ of all children injured required hospitalization. Not surprisingly, $70 \%$ of injuries occurred at home and on streets or footpaths. Head injuries accounted for $21.8 \%$ of all injuries, of which one quarter were intracranial injuries. Fractures $(31.3 \%)$ and sprains and strains $(21.1 \%)$ were common, and usually involved the upper limbs $(82.5 \%$ and $70.4 \%$ respectively).
It is hoped that increased public awareness and new legislation requiring the wearing of safety equipment while riding a scooter will contribute to a reduction in the number of scooter injuries.

$$
\begin{array}{r}
\text { M STOKES } \\
\text { M P CORBO } \\
\text { Victorian Injury Surveillance and Applied Research } \\
\text { System, } \\
\text { Monash University Accident Research Centre, } \\
\text { Monash University, Clayton, } \\
\text { VIC 3800, Australia } \\
\text { Maria.Corbo@general.monash.edu.au }
\end{array}
$$

\section{BOOK REVIEW}

UNICEF: A league table of child deaths by injury in rich nations. Innocenti Report Card No 2. February 2001. UNICEF Innocenti Research Centre, Florence, Italy

UNICEF has recently (February 2001) published the second of its "Innocenti Report Cards" entitled A league table of child deaths by injury in rich nations. It produces, for the first time, a standardized league table of the wealthiest nations (26 of the 29 OECD member states) ranking them according to deaths from unintentional and intentional injuries in 1-14 year old children. Using mortality data from WHO, injury deaths per 100000 children for the latest five year period, 1991-95, are presented, together with the rates for 1971-75. Many other data are presented, including a comparative table on national legislation related to injury prevention measures, and another which highlights where countries are ahead or behind in reducing deaths from specific causes.

Although there may be limitations related to the way the data are collected, the league table reveals that Sweden, the UK, Italy and the Netherlands fare best, with death rates below seven per 100000 . The worst are the USA, Portugal, Mexico and South Korea, where rates are three to four times higher. Variations are also shown in the relative progress made by OECD communities between 1971-75 and 1991-95. Canada has performed better than the USA in reducing child injury death rates; Australia better than New Zealand. Germany has performed best with rates falling by more than $70 \%$.

The UNICEF report highlights the likely strong association between injury deaths and social deprivation. However, it stresses the paucity of data at national levels linking injury death with the social and economic circumstances of families. The difficulty of identifying exactly which children are most at risk leads UNICEF to conclude that "all injury prevention policy [is] pitifully underinformed".

Although concerned with the situation in the wealthiest countries, the report concludes with a section on low income countries, pointing out that this is where $98 \%$ of all child injury deaths occur. UNICEF estimates that in the case of traffic accidents, 10000 children are killed each year in rich nations, for the rest of the world, the figure is close to 240000 per year.

While acknowledging the progress made in reducing child injury death rates since the 
1970s in OECD countries, the comparative data presented by UNICEF shows the wide gaps in progress made by wealthy countries. Many still have a long way to go before they match the rates found in Sweden, the UK, Italy, and the Netherlands.

The Report Card provides an advocacy tool, which can be used to stimulate interest internationally in childhood injury.

Copies of the Report Card are available from the web at: http://www.unicef-icdc.org./ publications/index.html

E TOWNER

J TOWNER Newcastle upon Tyne, UK

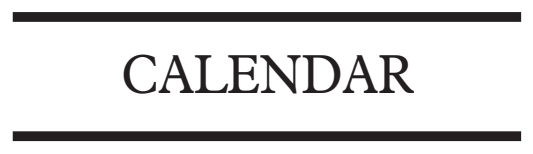

American Academy of Pediatrics National Conference and Exhibition

19-24 October 2001, San Francisco, California, USA. Section programs provide a forum for the discussion of clinical matters or research related to a particular subspecialty, including injury and poisoning. Further information: www.aap.org. 6th World Conference on Injury

Prevention and Control

12-15 May 2002, Montréal, Québec, Canada. The theme of the conference is injuries, suicide and violence: building knowledge, policies, and practices to promote a safer world. Further information: 6 th World Conference on Injury Prevention and Control, 511 place d'Armes, \#600, Montréal, QC H2Y 2W7, Canada (tel: +1 514 $8481133 /+18772138368$ (Canada/US), fax: $\quad+1 \quad 514288$ 6469, email: trauma@coplanor.qc.ca, web site: www.trauma2002.com).

\section{Cigarettes and fire}

The need to reduce the fires associated with cigarettes and the need to do so has been the subject of some discussion in Australia and New Zealand. Following research and discussion on regulation in the US a Private Members Bill calling for the Standards Council to draw up a safety standard for cigarettes was introduced into the New Zealand Parliament in November $2000 \mathrm{MP}$ and former fireman Grant Gillon. Noting that fires started by cigarettes are unusually lethal Mr Gillon welcomed the prospect of cigarettes that are less likely to start fatal fires. "Typically, a cigarette fire starts when someone drops their smoke. Since they're designed not to go out until they have been totally smoked, the cigarette will burn through a cushion or mattress cover and start a fire that smoulders for hours". The idea behind the Cigarettes (Fire Safety) Bill is that manufacturers could reduce this effect by reducing the diameter of the cigarette, reducing the density of tobacco packaging and reducing the porosity of cigarette paper (which allows less air to flow through the paper). "Cigarettes are the largest single cause of fire deaths. Twenty people are killed or injured in fires caused by cigarettes each year. This is simply about making cigarettes safer and saving lives". "Treating injuries related to smoking fires is estimated to cost $\$ 65$ million each year. That doesn't include lesser burns treated elsewhere or damage to property. It is better to spend a much smaller sum of money on fixing the problem by making cigarettes safer. "We have tried to cut down on fire deaths by educating the public and by introducing standards for the flammability of materials. These approaches are valuable, but there is one more step: the cigarette itself". Coverage of tobacco company claims to have produced a cigarette that is less likely to start fires if carelessly handled are also starting to appear in the Australian media (sources: www.alliance.org.nz and Melbourne Herald-Sun, 29 January 2001).

\section{A couple of "odd spots"....}

A Dutchman's driving test ended prematurely when his car was ripped apart by two trains. $\mathrm{He}$ and his examiner hurriedly escaped after stalling on a rail crossing near The Hague. Separate trains dragged the car in two directions but no-one was hurt (The Age (Melbourne), February 2001).

A Spanish priest caught drink-driving told police he had drunk too much communion wine because he'd celebrated six masses that day. He said he had to drive to reach the churches (The Age (Melbourne) February 2001). 